\title{
Testing the Role of Speech Perception in Loanword Adaptation Over Time*
}

\author{
Ponghyung Lee \\ Daejeon University, Daejeon City, South Korea
}

\begin{abstract}
This paper considers the role of speech perception and L2 phonological structures involved with a loanword adaptation. To this end, this study focuses on conducting nonlinear regression analyses on the correlation between the earlier and present day Korean loanwords from English and perception of the English stimuli found from Korean speakers. This attempt is based on the assumption that the level of relevant knowledge on the target language appears to be crucial in the determination of final results. Specifically speaking, it is presumed that in the Enlightenment Period, the knowledge on English was relatively low and hence it is expected that the proportion of phonetic perception was quite prevailing, compared to the share taken by L2 phonological structures, and the opposite will be the case with the current Korean. In the wake of nonlinear regression analyses, the author obtained skewed $R^{2}$ values 0.216 in the Enlightenment Period and 0.732 in Present-Day, respectively. On top of that, the reference line drawing an ogive curve in a scatter plot of Present-Day and a nondescript line found with the Enlightenment Period strongly bears out the contention in favor of speech perception position, instead of the position favorable to the role of L2 phonology.
\end{abstract}

Keywords: speech perception, L2 phonological structure, nonlinear regression, loanword adaptation

\section{Introduction}

The borrowed words have been observed to inevitably adjust themselves to befit the segmental and prosodic requirements of the recipient language. Owing to the attempts regarding this recalcitrant issue over 20 years since the seminal work of Silverman (1992), it comes to be possible to figure out the general landscape of the concerned processes which take place during the interaction between two involved languages, and what factors would be in charge of altering the input structures in a proper way. In general, three components have been believed to intervene: perception of L2 acoustic cues (e.g., Silverman, 1992; Peperkamp, Vendelin, \& Nakamura, 2008), L2 phonological structures (e.g., LaCharité \& Paradis, 2005, 2011), and orthography of donor languages (e.g., Vendelin \& Peperkamp, 2006). However, still this continuing controversy has not vanished in the light of the ensuing question: To what extent does each of the concerned components exert influence in the course of

\footnotetext{
* I would like to appreciate Robert Daland, Yanyan Sui, Mathhilde Hutin, Juhee Lee, Chin-Wan Jung among others for useful discussions at the fifth International Conference on Phonology and Morphology on July, 2014 held at Chonnam National University, South Korea. My sincere thanks also go to Youngju Yoon for his technical assistance for the statistical analyses of the sets of collected data. Without doubt, all errors remain mine.

Ponghyung Lee, professor, Ph.D., Department of English, Daejeon University.
} 
adaptation or transmission whatsoever? In the present paper, the author is going to address the previous model presented by LaCharité and Paradis $(2005,2011)$ on what the concerned three components engaged in mapping L2 input to L1 loanword output are really like. For the purpose, the author is trying to examine what has been occurring to borrowed words mostly from English during two temporal stages of Korean with the temporal disparity of around 100 years, that is, what is called the Enlightenment Period (from the 1880s to 1920s) and Present Day. One thing to be clarified from the outset is that among the three factors, the intervention of orthography is going to be overlooked, in the sense that both concerned periods parallel in terms of the conceivable spelling influence. As will be addressed below, the Enlightenment Period is characterized as era of limited knowledge on Indo-European languages, considering that Korean speakers had been rarely, nearly never, exposed to the Western culture up until that time. Nonetheless, it is believed that the extremely limited chances to converse with foreigners either through direct oral or written channel never guarantee an adverse effect against the potential influence of written text. By contrast, today's Korean society is, given an extensive chance to have a direct contact with native speakers of Indo-European, especially English, inundated with the flood of written English texts. However, the ubiquity of both orally and optically transmitted L2 inputs through TV, Internet or other recorded materials seems to enable neither oral nor written component to take a disproportionately large share in their intervention, contra the contention advanced by Peperkamp (2005), Yip (2006), and Vendelin and Peperkamp (2006), to name just a few.

The present paper is structured in the following way: The first section sets up the hypothesis on loanword adaptation and transmission, and tries to characterize two sets of loanword database and two sets of perception experiments. The second section concerns the results of nonlinear regression analyses conducted in an effort to test whether the convergence between perception of Korean speakers and loanword data is more solid in the Enlightenment Period than in Present-Day or not. These experimental results are significant for the purpose. Considering that since the Enlightenment Period is believed for Korean speakers to lack the extensive knowledge on the English language, it is expected that the role of grammatical knowledge on L2 at that time would have been more tenuous than in the contemporary Korean. The third section seeks the discussions and implications of the experimental results. The last section wraps up the present study.

\section{Investigating the Role: L2 Perception vs. Phonological Structures}

\section{The Hypothesis to Be Tested}

As pointed out in Section 1, loanword adaptation has been defined as a process of mapping either L2 perception or phonological inventories to L1 phonological structures, and the mapping appears to be affected by L2 orthography as well. Another notable thing, which has been overlooked in the previous literature, is that an entire speech community would be involved when a word undergoes an adaptation/transmission process, rather than just a single bilingual speaker, as argued by LaCharité and Paradis (2005, 2011). As noted by Crawford (2008), the spectrum ranging from a perfect monolingual to a bilingual community regarding the target L2 is prone to make a significant difference in their contribution. The overall assumptions are sketched below: 
(1) a. L2 phonological structures, perception, ${ }^{1}$ and orthography are engaged with loanword adaptation.

b. The whole speech community of L1 is involved with loanword adaptation/transmission.

On the basis on the assumptions given in (1), the author is going to experimentally test the hypothesis proposed by LaCharité and Paradis (2005, p. 223) recapitalized below in (2):

(2) a. Loanword adaptation is generally based on the L2 (not L1) referenced to perception of L2 phoneme categories.

b. Phonetic approximation (phonemic mismatching or nonperception of sounds) plays a limited role in loanword adaptation.

If L2 phonological structures are privileged to be influential while the role of perception is minimized in the decision of borrowed words, and bilingual speakers are leading the adaptation process, as supported by LaCharité and Paradis $(2005,2011)$, which goes squarely against the perception-first position, taken by Silverman (1992), Peperkamp et al. (2008), De Jong and Cho (2012) among others, it is expected that the share of L2 phonological structures increases and instead, perception diminishes as the increase of the number of bilingual speakers in the L1 community. In other words, phonetic perception is expected to come into playing a role to the utmost degree when the concerned period is far from being bilingual.

Under the setting, the author is going to examine what is happening to the words adopted in the earlier and contemporary periods spanning a temporal distance of hundred years or so in the history of the Korean language. The earlier stage refers to the Enlightenment Period (from the 1880s to 1920s) and ensuing a couple of decades, and at the time, the arguably exotic or mysterious words from Indo-European languages, mostly from English, came into existence for Korean for the first time. In other words, it would be safe to say that the Korean community at that time is defined as, by and large, monolingual. The inaccessibility to the donor languages justifies the presumption on what the linguistic situation was like a century ago. When examining the cross-section of the linguistic aspects of that time, proper nouns, specifically, place names, nationality, biblical personal names were found to take the lion's share. By contrast, undoubtedly in the present Korean community, the L2 knowledge has remarkably advanced through the public and private education opportunities and expanding contact with the target languages. What this means is that the current Korean speakers are extensively exposed to L2 phonological structures and oppositely, the role of perception stands a significant chance to shrink. The author is going to test that kind of hypothesis, examining whether the perception test results obtained from Korean learners of English do match the loanword databases of two relevant different periods.

If the assumption on the correlation between perception and L2 phonological structures in conjunction with the relevance of knowledge for the target language at the community level is legitimate, the perceptual results of Korean learners of English is going to more approximate the numerical values of those borrowed at the Enlightenment Period than those adopted nowadays. What is more, the relative convergence between L2 perception and the earlier borrowings would lend support to the hypothesis in favor of L2 phonological structures offered by LaCharite and Paradis $(2005,2011)$. On the other hand, when it proves to be a divergence, it would lead to conclude that the underpinning of the hypothesis would be seriously undermined.

\footnotetext{
${ }^{1}$ In this paper, what it means by the word "perception" stripped of any type of modification, is human perceiving activities interlocked with phonetic properties, putting aside phonological perception represented by the identification of grammatical categories such as phonemes, syllable structures, prosodic patterns of L2, and the like.
} 


\section{Two Sets of Loanword Resources}

The main sources of the earlier borrowings ranging from the 1880s to 1920s are as follows: Park (1997) Vocabulary of the Enlightenment Period 5: Loanwords, Min and Jang (2011) Annotation Dictionary of the Verses of the Enlightenment Period, and Kim (1999), Lee (2008), Park (1994). Meanwhile, as to the sources of current loanwords, for the most part, the current study relies on the corpora offered by the National Institute of the Korean Language (1991/2001) and the database built by Sechang Publishing Co. (1997).

Given that currently available loanword dictionaries are prone to be influenced by the prescriptive convention enforced by the National Institute of the Korean Language, it would be unsafe for the purpose to entirely rely upon either published dictionaries or the collections created by government agencies. For this reason, concerning some part of the data which are suspected to be warped by the prescription policy, the author has adopted the following strategy: To properly reflect the inter- and intra-personal variations regarding L1 regularities like consonantal tensification and aspiration, etc., the author tried to either consult Korean speakers or check out the cyber space to seek what is really happening to the current loanword situation.

In the collection of borrowings introduced in the Enlightenment Period, it would be essential to delineate explicitly what it refers to loanwords in the discussion. Specifically, the present study tries to confine loanwords to those ones directly from the donor languages to Korean without intervention of intermediary languages. In this sense, an extra precaution is called upon for the Enlightenment Period. Linguistically speaking, surrounding the turn of century, Korean community was facing a sociolinguistic context vulnerable to be affected by the Chinese and Japanese sociopolitical influence to a great extent. Thus, loanwords mostly categorized as proper nouns like personal and place names rarely evaded the linguistic impact of the two neighboring languages. Thus, getting rid of the borrowings via Chinese and Japanese would be the very first step to secure the quintessence of loanwords at that time. In this sense, the study removes e.g., Russia [arasa, rosəa], Germany [təkkuk], France [pəpkuk], America [mikuk], which evidently went into Korean via Chinese, and English [joykili] via Japanese from further consideration.

On the basis on this principle, the collection of loanwords borrowed during the Enlightenment Period amounts to 643 types, and from the viewpoint of tokens, they augment to 736 when this study incorporates the variants of every single L2 word. For instance, quadruplets concerning the final sibilant source [ $\theta]$ as $[\operatorname{simit} \dot{i}] /\left[\operatorname{simit}^{\mathbf{h}} \dot{i}\right] /[\operatorname{simis} \dot{i}] /[\operatorname{simis} \mathfrak{i}]$ manifest from the personal name Smith and triplets $[\mathbf{k a i f}$ eri $] /\left[\mathrm{f}^{\prime}\right.$ 'aifferi $] /\left[\mathbf{k}^{\mathbf{h}}\right.$ aifferi] from Kaiser are found. However, the author tried to rule out the variants from a

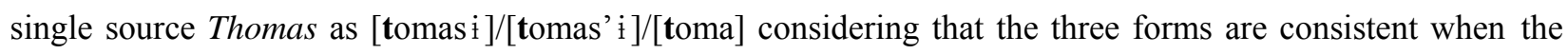
author focuses on the initial stop consonant [t]. Table 1 shows the number and percentage of the manifestation of borrowings with respect to the horizontally arrayed obstruent consonants of L2.

The second dataset of borrowings comprises the equivalents of the present day in parallel with every concerned words collected from the texts written during the Enlightenment Period. For the most part, the corpus established by Sechang Publishing Co. serves the purposes in an adequate way, considering that this database includes a hoard of personal and place names unlike others, which usually cast an only casual glance at proper nouns for the most part. Notice that the vast majority of the loanwords found in the earlier literature published in the end of 19th and the earlier part of the 20th centuries belong to proper nouns. The number of borrowings collected for the current period is, for that reason, practically the same as the earlier period. To be more precise, 
the numbers of types are exactly identical but that of tokens are slightly different. Regarding 643 borrowings, much reduced number of additional forms noticed, namely 14 forms are added in the contemporary Korean. As noted by Y. J. Kang (2010), the tapering of the inconsistency would be owing to the regularization of loanword adaptation by school institution and/or governmental language policies, which typically occurs over time in loanword adaptation. Table 2 gives the number and rate of consonant realization of the concerned loanwords in the present day Korean.

Table 1

The Statistics of Loanwords: The Enlightenment Period (1885-the 1920s) ${ }^{2}$

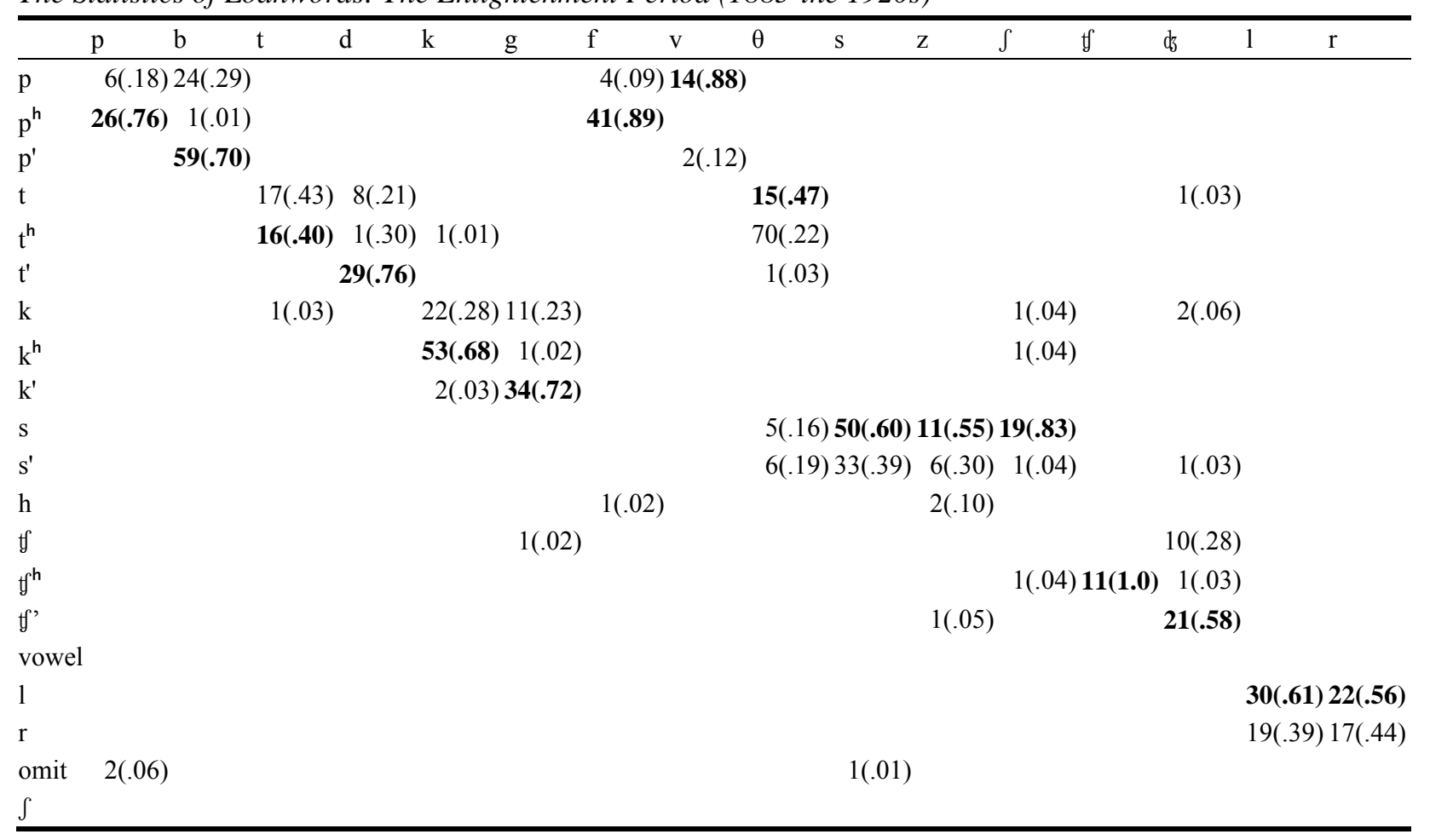

\section{Table 2}

The Statistics of Loanwords: Present-Day

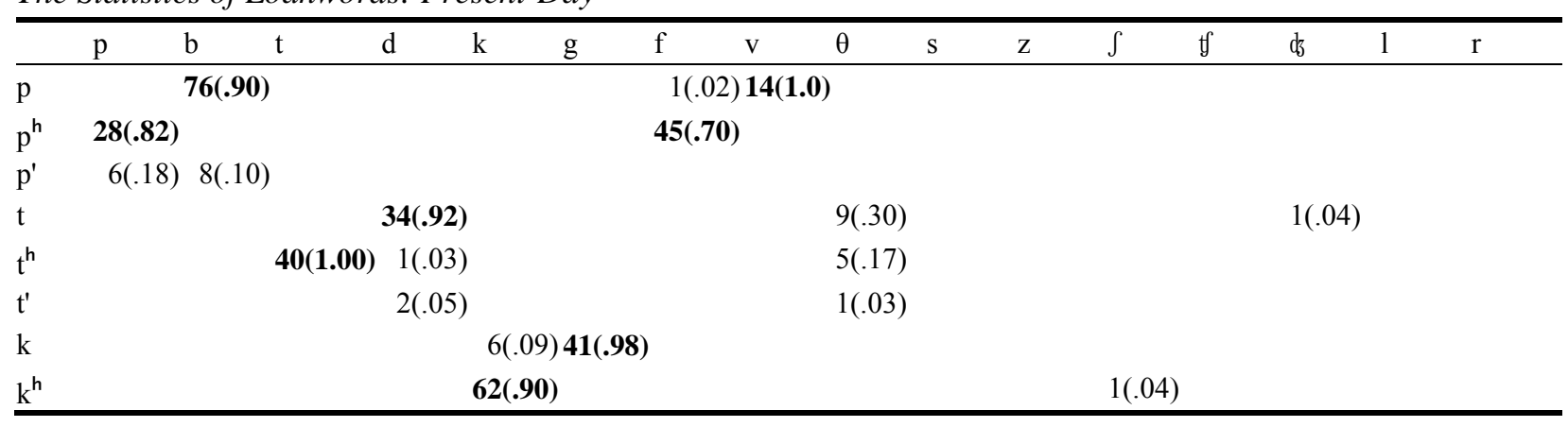

\footnotetext{
${ }^{2}$ Digital figures in each cell represent the number of words containing the concerned consonants followed by the parenthesized decimals representing the mapping rates of the relevant L2 consonants, which are horizontally plotted, in proportion to Korean sounds, which are vertically arrayed. The same thing applies to Table 2 below. The modal instantiations are highlighted by means of boldfaces.
} 


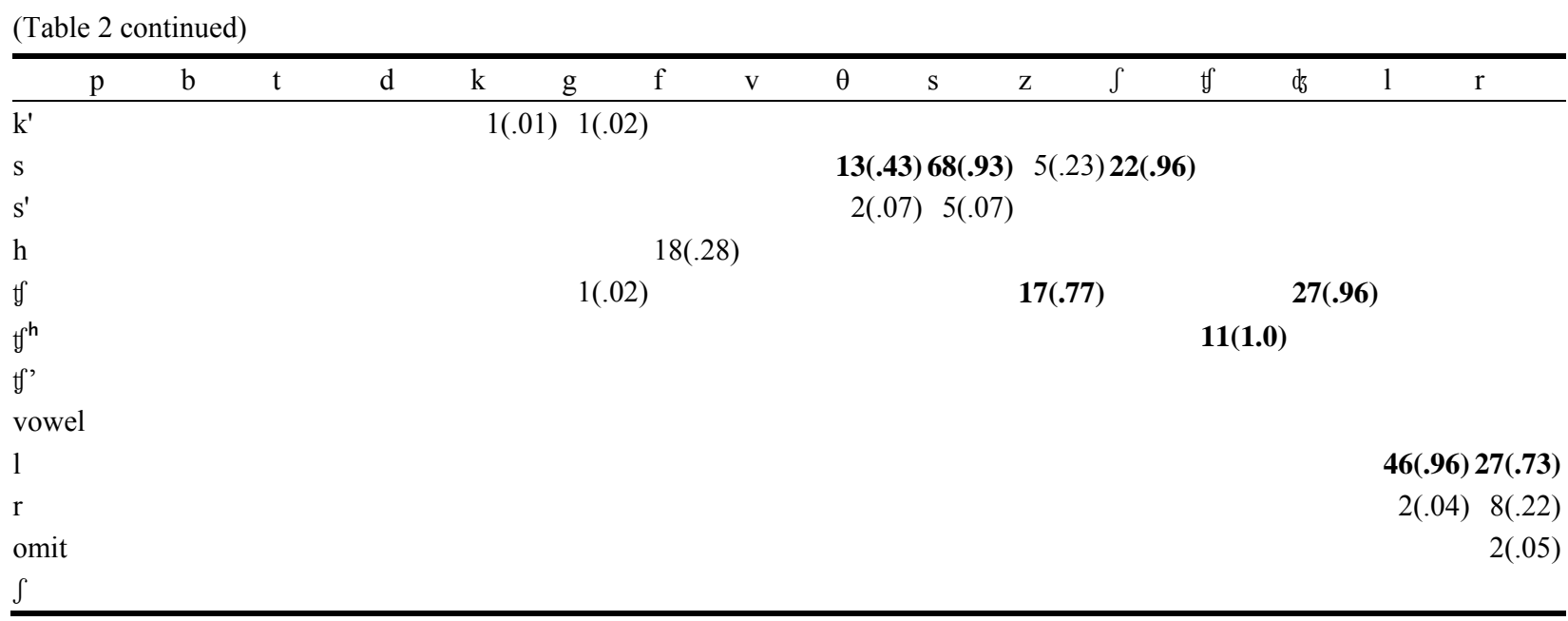

\section{Two Sets of Speech Perception Data}

Schmidt (1996). The classic view on the typical foreign accents in the second language acquisition is that, as Weinreich (1953) puts forth, it is due to the substitution of L1 sounds for the similar L2 sounds. When the substituting L1 sounds does not ever correspond to the targeted L2 sounds, accented speech unavoidably arises. The similarity and dissimilarity is yet to be further defined, and their interconnections with phonemic and allophonic contrast all the more complicate the situation. However, to pursue the perceptual relevance to the second language acquisition, it is misguided to entirely rely on one or two phonetic cues. It needs to remind the readers of the fact that every engaged practitioner is still unsuccessful in understanding what is definitely responsible for the identification judgment of similarity across languages. For instance, as De Jong and Cho (2011) indicate, it is never well-grounded to use voice onest time (VOT) as a criterion to compare English plosives and Spanish alternatives, and to compare English vowels and French vowels solely making use of F1 and F2, as tried by LaCharité and Paradis (2005). That point is important since in spite of the determinant quality of the individual acoustic cues, the consequences of their combinatory nature are still unknown. This would be the rationale in accounting for the process of loanword adaptation on the basis of perceptual recognition of L2 sounds as a whole rather than on their individual acoustic features.

As a breakthrough for the impasse, Schmidt's (1996) perception experiment using Korean subjects are quite pioneering. The experiment was designed to fulfill the task of giving the mapping reality between an array of English word-initial consonants to Korean consonants, as you can see in the matrix given in Table 3.

Table 3

The Statistics of Perception of Korean Subjects: Adapted From Schmidt (1996)

\begin{tabular}{|c|c|c|c|c|c|c|c|c|c|c|c|c|c|c|c|c|}
\hline & $\mathrm{p}$ & $\mathrm{b}$ & $\mathrm{t}$ & $\mathrm{d}$ & $\mathrm{k}$ & $\mathrm{g}$ & $\mathrm{f}$ & $\mathrm{v}$ & $\theta$ & $\mathrm{s}$ & $\mathrm{z}$ & $\int$ & t5 & $d s$ & 1 & $\mathrm{r}$ \\
\hline $\mathrm{p}$ & 0.03 & 0.42 & & & & & 0.06 & 0.94 & 0.03 & & & & & & & \\
\hline$p^{h}$ & 0.97 & 0.02 & & & & & 0.57 & & 0.16 & & & & & & & \\
\hline $\mathrm{p}^{\prime}$ & & 0.53 & & & & & 0.14 & & 0.08 & & & & & & & \\
\hline $\mathrm{t}$ & & & & 0.83 & & & & 0.05 & 0.03 & & & & & & & \\
\hline$t^{h}$ & & & 0.93 & & & & & & 0.03 & & & & 0.01 & & & \\
\hline $\mathrm{t}^{\prime}$ & & & 0.03 & 0.17 & & & & & 0.17 & & & & & & & \\
\hline
\end{tabular}


(Table 3 continued)

\begin{tabular}{|c|c|c|c|c|c|c|c|c|c|c|c|c|c|c|c|c|}
\hline & $\mathrm{p}$ & $\mathrm{b}$ & $\mathrm{t}$ & $\mathrm{d}$ & $\mathrm{k}$ & $\mathrm{g}$ & $\mathrm{f}$ & $\mathrm{v}$ & $\theta$ & $\mathrm{s}$ & $\mathrm{z}$ & $\int$ & t & $d \vec{c}$ & 1 & $r$ \\
\hline $\mathrm{k}$ & & & & & 0.06 & 0.49 & & & & & 0.02 & & & 0.01 & 0.01 & \\
\hline $\mathrm{k}^{\mathrm{h}}$ & & & & & 0.88 & & & & & & & & & & & \\
\hline $\mathrm{k}^{\prime}$ & & & & & 0.03 & 0.49 & & & & & & & & & & \\
\hline $\mathrm{s}$ & & & & & & & 0.02 & & 0.04 & 0.32 & & 0.51 & & & & \\
\hline$s^{\prime}$ & & & 0.02 & & & & 0.05 & & 0.44 & 0.67 & & 0.48 & & & & \\
\hline h & & & & & & & 0.14 & & & & & & & & & \\
\hline$t$ & & & & & & & & & & & 0.94 & & 0.06 & 0.80 & & \\
\hline$t^{h}$ & & & & & & & & & & & & & 0.91 & & & \\
\hline tf' & & & & & & & & & & & 0.03 & & 0.02 & 0.19 & & \\
\hline 1 & & & & & & & & & & & & & & & 0.99 & 1 \\
\hline$r$ & & & & & & & & & & & & & & & & \\
\hline
\end{tabular}

Design of perception experiment of Korean subjects. The author tries to reorient a perception test from the previous ones on the following grounds. First, the subjects employed in the listening experiment by Schmidt (1996) are Koreans residing in America. Their average length of living in America is reported to be three years. That means that the Korean natives are apt to be considerably influenced by the ambient language of the English language. Another experiment organized by Park and De Jong (2008) tries to make up for the inherent problem of Schmidt (1996) by replacing the subjects by Koreans residing in the Korean soil. Another is that Schmidt's experiment considered only 10 obstruent consonants among 24 contrastive consonants. In the experiment, the author tries to increase the number of examined consonants to 16 , excluding $/ \mathrm{m} \mathrm{n} \mathrm{j} \mathrm{j} \mathrm{w} /$ which have no significant phonetic disparity between Korean and English, and / 3 3/, which show disproportionately restricted distribution. ${ }^{3}$

The stimuli were created by reading 48 types of nonce words which contain the concerned 16 consonants in the pre-, post-, and intervocalic positions by a native of American English in his early 30s. The sounds were recorded employing Sennheiser head-mounted microphone (model PC31) and saved as WAV files using Praat. Each type of stimuli was played by Windows Media Player which was installed at the desktop computer built in a classroom lectern. The subjects consist of 21 females and 10 males aging from 21 to 28 . They were modestly paid for their participation, which lasted for 20 minutes. Each stimulus was followed by a pause lasting for two seconds. Furthermore, to boost concentration of the subjects, 48 stimuli were divided into four subgroups and one minute breaks were allowed at the end of each subgroup. The experiment was preceded by a practice session and each stimulus was repeated twice in the carrier phrase "I say ." The subjects were directed to write down what they heard in Korean scripts, which were judged to be the closest to the English stimuli, as exemplified in Appendix A. The obtained tokens amount to 1,646, as given in Table 4.

Table 4

The Statistics of Perception of Korean Subjects: Present Study

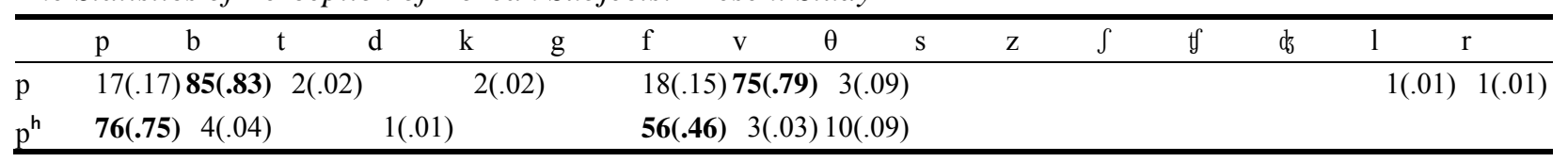

\footnotetext{
${ }^{3}$ At first, the author tried to measure goodness rates of the mapping between the stimuli and the experimental responses. However, since the experimental results seem to lack consistency in pattern, e.g., in terms of congruence of modal responses and goodness rates, the results are given up in the discussion and put aside as Appendix B.
} 


\begin{tabular}{|c|c|c|c|c|c|c|c|c|c|c|c|c|c|c|}
\hline & $\mathrm{p}$ & $\mathrm{b}$ & $\mathrm{t}$ & $\mathrm{d}$ & $\mathrm{k}$ & $\mathrm{g}$ & $\mathrm{f}$ & $\mathrm{v}$ & $\mathrm{s}$ & $\mathrm{z}$ & $\int$ & $d 3$ & 1 & $\mathrm{r}$ \\
\hline $\mathrm{p}^{\prime}$ & $1(.01)$ & $7(.07)$ & & & & & $38(.31)$ & $4(.04)$ & & & & & & \\
\hline $\mathrm{t}$ & & & $16(.15) 7$ & $78(.76)$ & & & $1(.01)$ & & $14(.13)$ & & & & & \\
\hline$t^{h}$ & & & $80(.76)$ & $1(.01)$ & & & $1(.01)$ & & $7(.06)$ & & & & & \\
\hline$t^{\prime}$ & & & $1(.01)$ & $3(.03)$ & & & $1(.01)$ & & $51(.47)$ & & & & & \\
\hline $\mathrm{k}$ & $4(.04)$ & & $5(.05)$ & $7(.07) 2$ & $21(.19) 7$ & $74(.76)$ & & & $4(.04)$ & & & & & \\
\hline $\mathrm{k}^{\mathrm{h}}$ & & & $1(.01)$ & & 82(.74) & $2(.02)$ & & & $1(.01)$ & & & & & \\
\hline $\mathrm{k}^{\prime}$ & & & & & & $1(.01)$ & & & $2(.02)$ & & & & & \\
\hline $\mathrm{s}$ & & & & & & & & & $1(.01) 17(.16)$ & $6(.10)$ & $6(.06)$ & & & \\
\hline$s^{\prime}$ & & & & & & & & & $4(.04) 60(.55)$ & $1(.02)$ & $3(.03)$ & & & \\
\hline $\mathrm{h}$ & & & & $1(.01)$ & & & $6(.05)$ & & $1(.01)$ & & & & & $2(.01)$ \\
\hline t & & & & $1(.01)$ & & & & & $29(.27)$ & $55(.89)$ & & $5(.05) \mathbf{7 8}(.76)$ & & \\
\hline$t^{h}$ & & & & & & & & & $1(.01)$ & & & $\mathbf{9 1}(.93) 20(.20)$ & & \\
\hline tf & & & & & & & & & $1(.01)$ & & & $2(.02) \quad 4(.04)$ & & \\
\hline vowel & & $2(.02)$ & & $1(.01)$ & $1(.01)$ & & & $9(.09)$ & & & & & $30(.30)$ & $2(.01)$ \\
\hline 1 & & & & & & $8(.08)$ & & & & & & & $55(.55) 5$ & $51(.38)$ \\
\hline r & & & & & & $1(.01)$ & & & & & & & $14(.14) 8$ & $81(.60)$ \\
\hline omit & & $4(.04)$ & & $9(.09)$ & $5(.05) 1$ & $12(.12)$ & & & $15(.14)$ & & & & & \\
\hline $\int$ & & & & & & & & & $1(.01)$ & & $89(.91)$ & & & \\
\hline
\end{tabular}

\section{Analyses and Discussion}

On the basis of the collected database (Tables 1 and 2) and the results of perception test (Table 3), the author tries to investigate the convergence/divergence between loanwords and perception results separately with the two concerned periods. As part of the efforts in search of the correlation between phonetic perception and loanword adaptation, at first, the current study attempts to investigate the convergence or divergence between the perception level given by Schmidt (1996), which is given by Table 3, and what happens to loanword adaptations brought about in the early period of the Enlightenment Period and those of Present-Day. This analysis would work as a pilot study for the purpose. To fulfil the intended goal, this study attempted a nonlinear regression analyses to obtain the $R^{2}$ values and reference lines using Equation (1): Loanword rates work as dependent variable and perception rates serve as independent variable:

(1) Equation for nonlinear correlation between loanwords and perception:

$$
y=1 /(1+\operatorname{Exp}(-(a+b * x))) .
$$

Parameters $a$ and $b$ are decided in the course of nonlinear regression analyses. Here the present study obtained the values $a=-1.962, b=2.711$ (the Enlightenment Period): $a=-2.695, b=5.433$ (Present-Day). The results of the statistical analyses are shown in Figure 1 and Figure 2.

What is significant in the present pilot study is that the coefficients between perception and loanword adaptation are significantly higher in the contemporary Korean than those in the early period: The values of $R^{2}$ are 0.365 and 0.658 , respectively. Another thing is the reference line of Figure 2 much more takes the shape of an ogive curve than in Figure 1. This overall fact leads readers to be skeptical about the L2 phonology-driven analysis and instead, seems to lend support to the perception-driven analysis in the matter of loanword adaptation. 


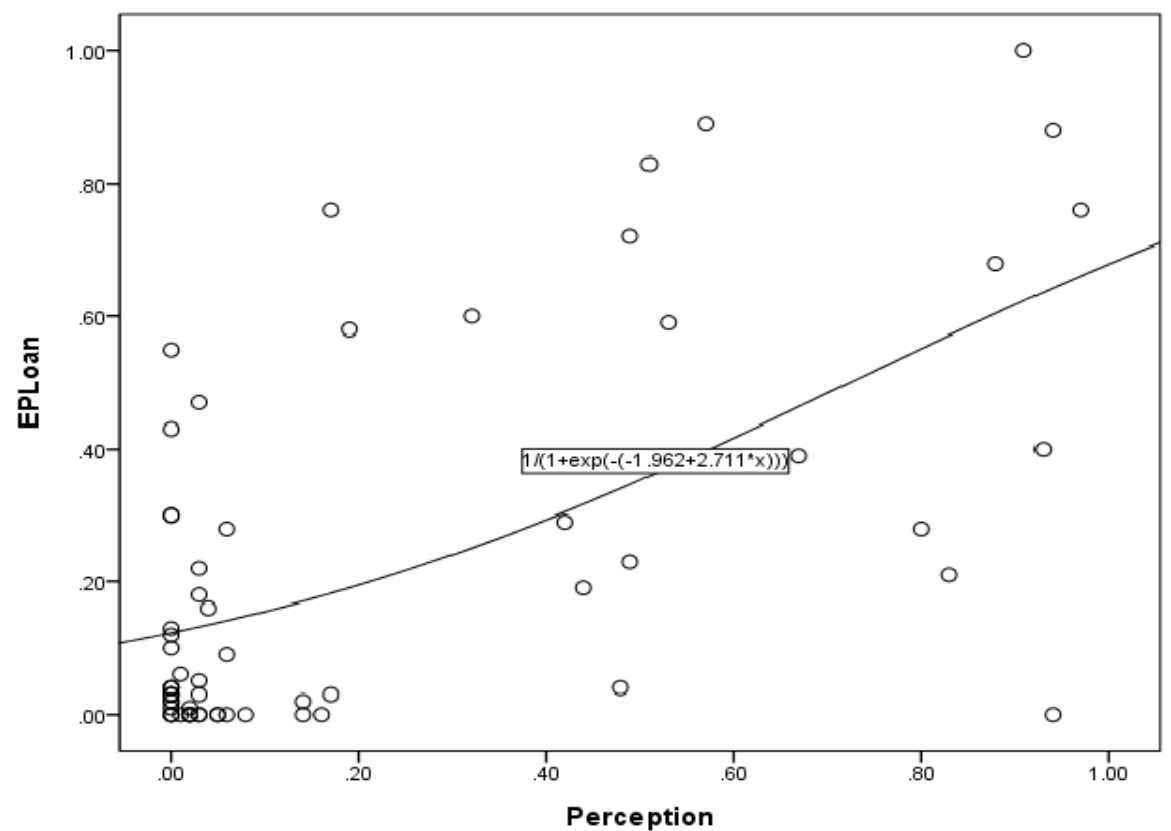

Figure 1. A pilot study: the correlation between perception and loanword adaptation: The Enlightenment Period.

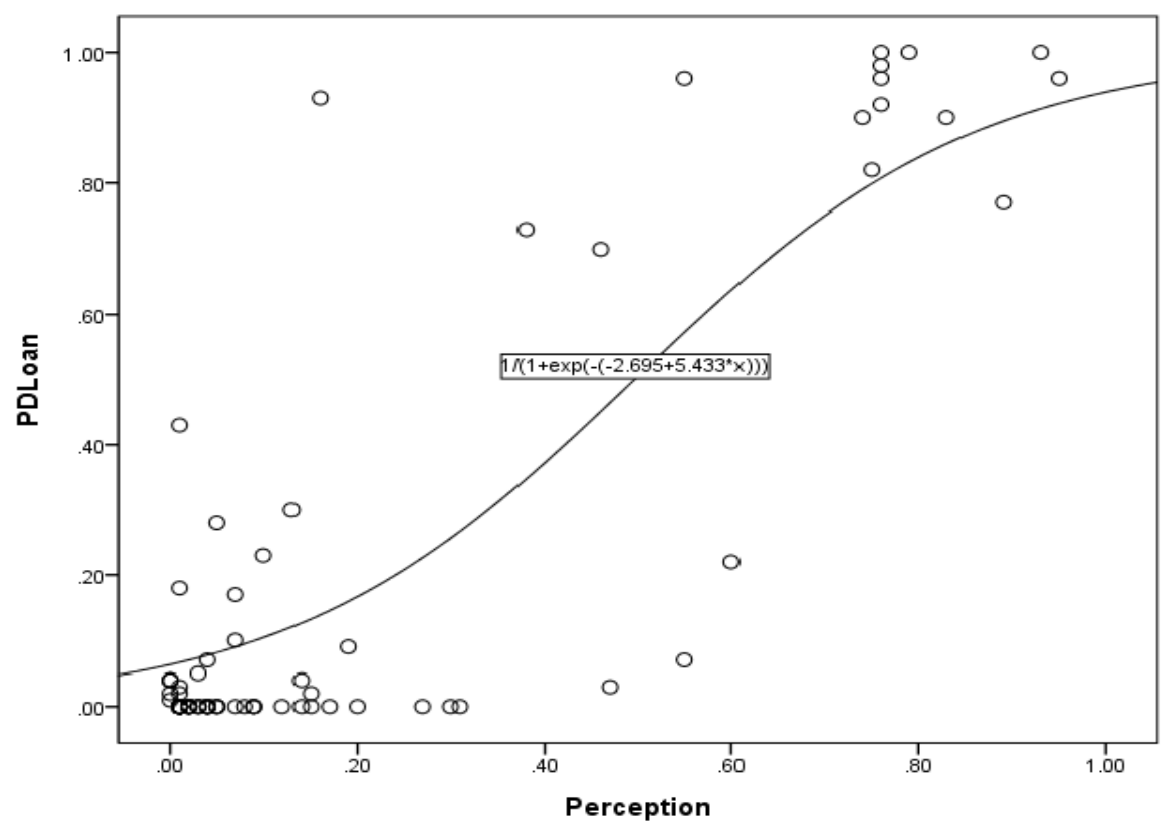

Figure 2. A pilot study: the correlation between perception and loanword adaptation: Present-Day.

Now, it is time to turn the attention to consider whether the coefficients resulted from the regression analysis of perception rates given by Table 4 and loanword adaptation rates given in Tables 1 and 2. As illustrated by scatter plots below, in which the reference line in Figure 4 all the more clearly shows an ogive curve than that in Figure 3. The values of parameters $a$ and $b$ are -2.111 and 2.522, respectively in Figure 3; -3.636 and 7.005, respectively in Figure 4. And the author obtained the values of $R^{2}: 0.216$ in Figure 3 and 0.762 in Figure 4, respectively. Again, the statistical results firmly bear out the contention that loanword adaptation is mainly driven by phonetic perception, instead of L2 phonological structures. 


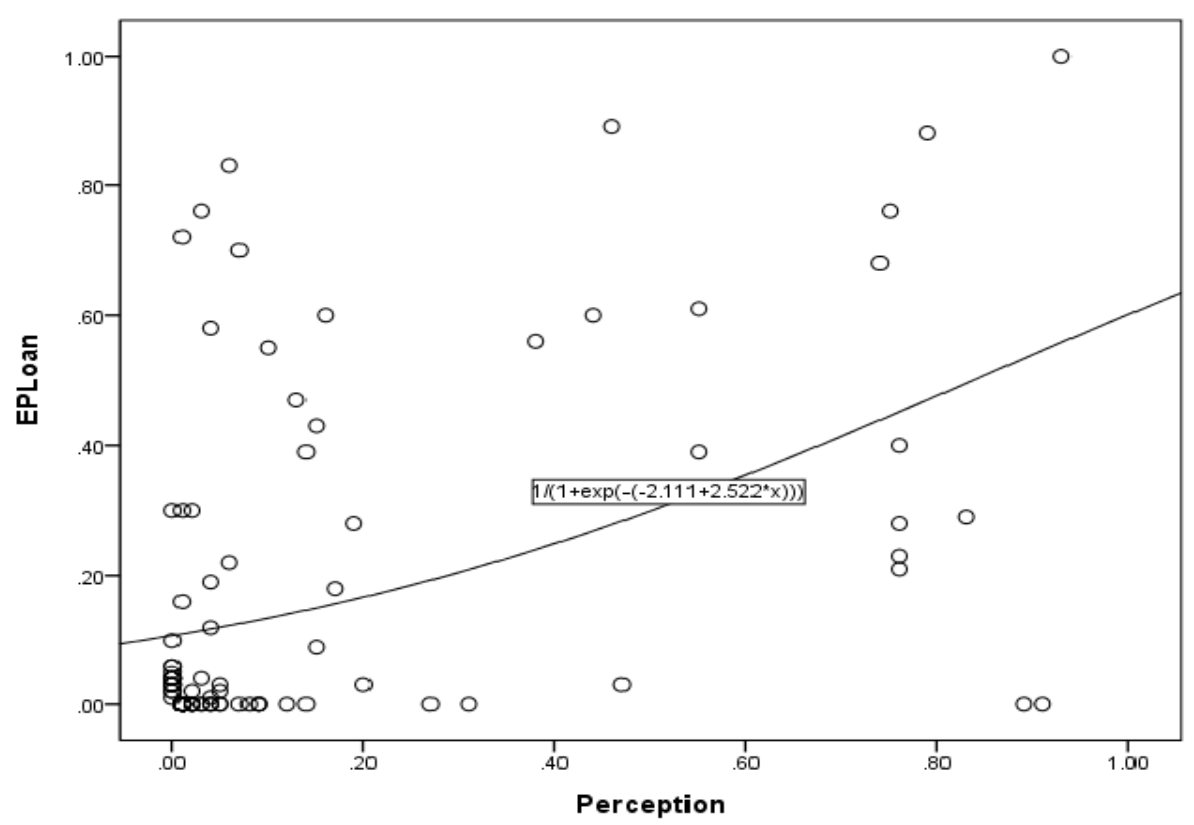

Figure 3. Correlation between perception and loanwords: The Enlightenment Period.

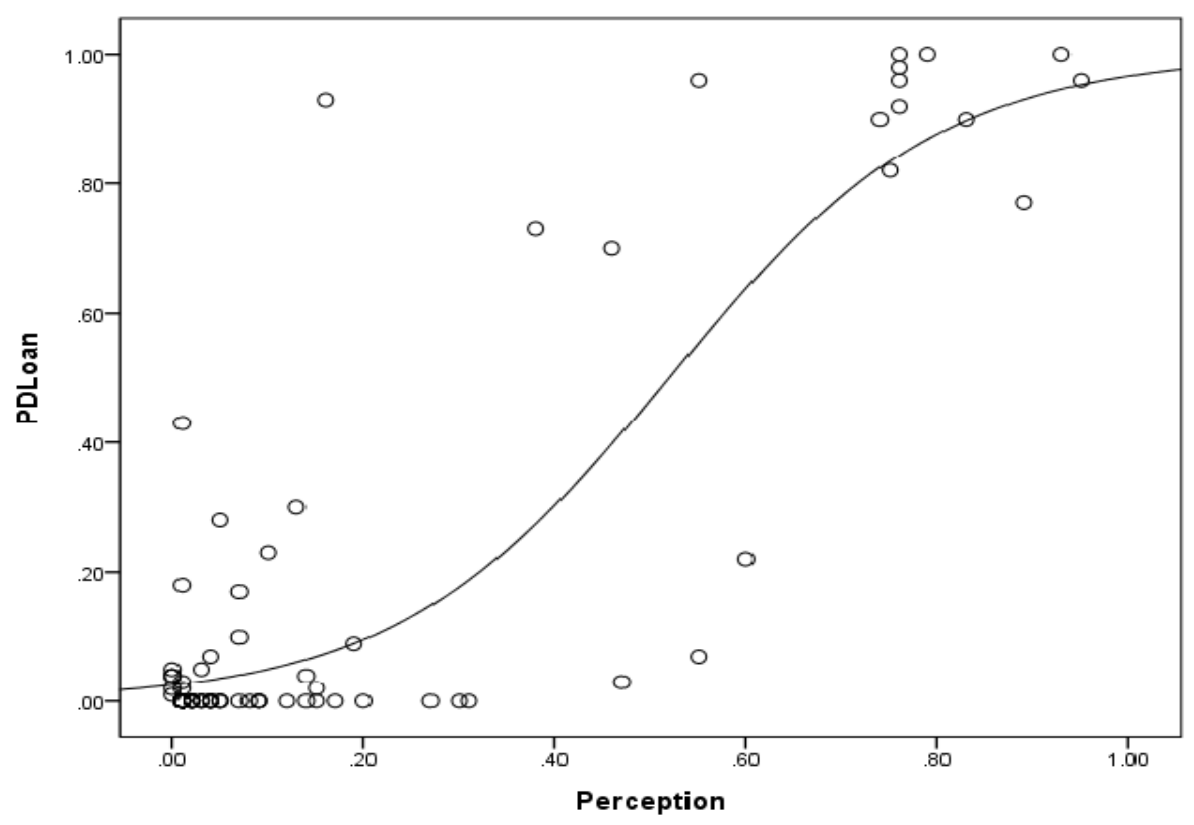

Figure 4. Correlation between perception and loanwords: Present-Day.

\section{Conclusion}

The available statistics and scatter plots for the Enlightenment Period and Present-Day prove to be consistent in showing significant differences in concerned coefficients. The convergence between Present-Day loanwords and phonetic perception is markedly higher than in the case of the Enlightenment Period. What the statistics resulted from the regression analyses seems to evidently lend support to the perception-driven position (Peperkamp et al., 2008 among others) in loanword adaptation, opposing L2 phonology-driven position (LaCharité \& Paradis, 2005 among others). However, the concerned practitioners must be cautious about the 
experimental results. In spite of supporting the perception-driven propensity in processing newly incoming words, they do not, as such, disapprove the symbiotic interplay between perception and L2 phonology. The available results should be understood as making explicit the dominant role of speech perception, compared to the subsidiary role of L2 phonological structures.

One outstanding problem remains to the present investigation. It is possible that not only adaptation pattern but also phonetic perception is susceptible to change over time, in other words, to what extent is the current approach valid in light of linguistic perception of input materials applying to the diachronically different periods? This question would be an open-ended question. The author speculates that phonetic perception is not isolated from other human perception like visual, smelling, tasting, tactile perception, etc. However, it might be legitimate to conjecture that phonetic perception is markedly affected by the native language. What is at issue at this moment is that the aspects of the Korean language are not identical with respect to the concerned periods spanning 100 years or so, the Enlightenment Period and Present-Day, as was taken into consideration by the previous literature like Silva (2006) and Lee (2013) among others. Nonetheless, every researcher has a rare chance to access what the phonetic perception might have been like in the end of the 19th and early 20th centuries. Due to the methodological limitation, they are forced to disregard the change over time entangled with phonetic perception seemingly interconnected with the loanword transmission at stake.

\section{References}

Crawford, C. J. (2008). Adaptation and transmission in Japanese phonology (Doctoral dissertation). Cornell University.

De Jong, K., \& Cho, M. -H. (2012). Loanword phonology and perceptual mapping: Comparing two corpora of Korean contact with English. Language, 88(2), 341-368.

Kang, Y. J. (2010). The emergence of phonological adaptation from phonetic adaptation: English loanwords in Korean. Phonology, 27, 225-253.

Kim, H. -C. (1999). The Korean vocabulary in the Enlightenment Period. On the Development of the Korean Language over Time, 4, 115-162.

LaCharité, D., \& Paradis, C. (2005). Category preservation and proximity versus phonetic approximation in loanword adaptation. Linguistic Inquiry, 36, 223-258.

Lee, J. -Y. (2008). The acceptance of foreign geographical names in Korean: On the geographical books on the world from the late 19 th to early 20th centuries. Kukekukmunhak, 150, 130-155.

Lee, P. (2013). Loanword phonology. Seoul: Hankook Munhwasa.

Min, C., \& Jang, S. -N. (2011). Annotation dictionary of the verses in the Enlightenment Period. Seoul: Bogosa.

Paradis, C., \& LaCharité, D. (2011). Loanword adaptation: From lessons learned to findings. In J. Goldsmith, J. Rigglr, \& A. C. L. $\mathrm{Yu}$ (Eds.), The handbook of phonological theory (pp. 751-778). Malden, MA: Blackwell Publishing.

Park, H., \& De Jong, K. (2008). Perceptual category mapping between English and Korean prevocalic obstruents: Evidence from mapping effects in second language identification skills. Journal of Phonetics, 36, 704-723.

Park, Y. -S. (1994). The vocabulary of the newspaper in the Enlightenment Period. Papers of Gangnam University, 25, 55-80.

Park, Y. -S. (1997). The vocabulary of the Enlightenment Period Korean. Part 5: Loanwords [in Korean]. Seoul: Pagijung.

Peperkamp, S. (2005). A psycholinguistic theory of loanword adaptations. In M. Ettlinger, N. Fleischer, \& M. Park-Doob (Eds.), Proceedings of the 30th Annual Meeting of the Berkeley Linguistics Society (pp. 341-352). Berkeley, CA: Berkeley Linguistics Society.

Peperkamp, S., Vendelin, I., \& Nakamura, K. (2008). On the perceptual origin of loanword adaptation: Experimental evidence from Japanese. Phonology, 25, 129-164.

Schmidt, A. M. (1996). Cross-language identification of consonants. Part 1. Korean perception of English. Journal of Acoustical Society of America, 99, 3201-3211.

Sechang Publishing Co. (1995). The usage in the transcription of loanwords. Seoul: Sechang Publishing Co..

Silva, D. (2006). Acoustic evidence for the emergence of tonal contrast in contemporary Korean. Phonology, 23, 287-308. 
Silverman, D. (1992). Multiple scansions in loanword phonology: Evidence from Cantonese. Phonology, 9, $289-328$.

The National Institute of the Korean Language. (1991/2001). The current usage of loanwords [in Korean]. Seoul: The National Institute of the Korean Language.

Vendelin, I., \& Peperkamp, S. (2006). The influence of orthography on loanword adaptation. Lingua, 116, 996-1007.

Weinreich, U. (1953). Language in contact. The Hague, Netherlands: Mouton.

Yip, M. (2006). The symbiosis between perception and grammar in loanword phonology. Lingua, 116, 950-975.

\section{Appendix A: Perception Test for Korean Speakers for 48 English Stimuli}

\section{Stimuli creation}

Read each of the following nonsense English words two times. Please read within the carrier sentence format:

"Number 1. I say ." "I say

initial

(1) fa (2)va (3) $\theta \mathrm{a}$ (4)sa (5)ra (6) la (7)ra (8) $\mathrm{fa}$

(9) $f a$ (10) dza (11)pa (12) ba (13)ta (14) da (15) ka (16) ga

final

(1) af (2) av (3) $\mathrm{a} \theta$ (4) ar (5) $\mathrm{al}$ (6) $\mathrm{as} \mathrm{(7)} \mathrm{az}$ (8) $\mathrm{a} \int$

(9)a3 (10)aff (11)ap (12)ab (13)at (14) ad (15)ak (16)ag

medial

\begin{tabular}{|c|c|c|c|c|c|c|}
\hline (1) afa & (2) ava & (3) $\mathrm{a} \theta \mathrm{a}$ & (4) ara & (5)ala & (6) asa & (7) aza \\
\hline (9)atfa & (10) adza & (11) apa & (12) aba & (13) ata & (14) $\mathrm{ada}$ & (15)aka \\
\hline
\end{tabular}

\section{Perception test}

You will hear the nonce words spoken by an English native speaker. We have two tasks to be done by you. First, please write down those nonsense words he heard in Korean alphabet. Second, indicate how similar your choice and the consonant you indicated in Korean alphabet to the sound you heard by check-making the number among seven points on a Likert scale.

ta 다, 타

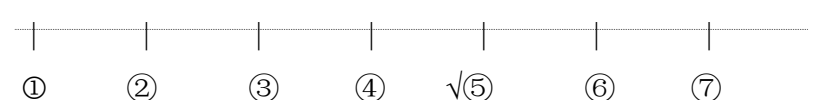

ba 바, 빠, 파

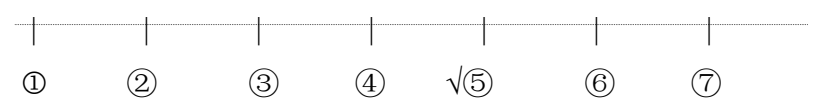

$\operatorname{ara}$ 알라, 아라

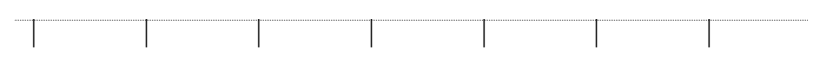

(1) (2) (3) (4) (5) (6) (7)

apa 아파, 아빠

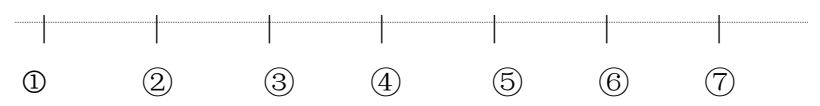


SPEECH PERCEPTION IN LOANWORD ADAPTATION OVER TIME

Appendix B: Goodness Test for Korean Speakers for 48 English Stimuli ${ }^{4}$

\begin{tabular}{|c|c|c|c|c|c|c|c|c|c|c|c|c|c|c|c|c|}
\hline & $\mathrm{p}$ & b & $\mathrm{t}$ & d & $\mathrm{k}$ & $\mathrm{g}$ & $\mathrm{f}$ & $\mathrm{v}$ & $\theta$ & $\mathrm{s}$ & z & $\int$ & t & do & 1 & $\mathrm{r}$ \\
\hline $\mathrm{p}$ & $84(4.9) 4$ & $414(5.2)$ & $5(2.5)$ & $2(2.0)$ & & & $78(6.5)$ & $345(4.8)$ & $9(4.5)$ & & & & & & $4(3.5)$ & \\
\hline $\mathrm{p}^{\mathrm{h}}$ & $431(6.0)$ & $8(4.0)$ & & $4(4.0)$ & & & $207(4.1)$ & $9(3.0)$ & $30(3.3)$ & & & & & & & \\
\hline $\mathrm{p}^{\prime}$ & $5(2.5)$ & $29(4.8)$ & & & & & $127(5.1)$ & $5(2.5)$ & & & & & & & & \\
\hline $\mathrm{t}$ & & & $45(3.2)$ & $343(4.8)$ & & & & & $45(3.8)$ & & & & & & & \\
\hline$t^{h}$ & & & $308(4.2)$ & & & & & & $5(5.0)$ & & & & & & & \\
\hline $\mathrm{t}^{\prime}$ & & & & $12(4.0)$ & & & & & $234(4.9)$ & & & & & & & \\
\hline $\mathrm{k}$ & $16(4.0)$ & & $7(1.8)$ & $22(2.8)$ & $85(5.3)$ & $362(4.7)$ & & & $12(4.0)$ & & & & & & & \\
\hline $\mathrm{k}^{\mathrm{h}}$ & & & $3(3.0)$ & & $415(5.4)$ & $9(4.5)$ & & & & & & & & & & \\
\hline $\mathrm{k}^{\prime}$ & & & & & & & & & $5(5.0)$ & & & & & & & \\
\hline $\mathrm{s}$ & & & & & & & & & & $54(4.2)$ & $8(4.0)$ & $12(6.0)$ & & & & \\
\hline $\mathrm{s}^{\prime}$ & & & & & & & & & $18(4.5)$ & $307(5.6)$ & $2(2.0)$ & $7(7.0)$ & & & & \\
\hline $\mathrm{h}$ & & & & $4(4.0)$ & & & $14(3.5)$ & & & & & & & & & \\
\hline t & & & & $2(2.0)$ & & & & & & $136(5.4)$ & $79(5.1)$ & & & $406(5.5)$ & & \\
\hline$t^{h}$ & & & & & & & & & & & & & $518(5.6)$ & $69(4.1)$ & & \\
\hline t' & & & & & & & & & & & & & & $6(6.0)$ & & \\
\hline vowel & & & & $3(3.0)$ & & & & $33(4.7)$ & & & & & & & $157(5.1)$ & \\
\hline 1 & & & & & & $22(3.7)$ & & & & & & & & & $252(5.1)$ & $83(4.3)$ \\
\hline$r$ & & & & & & & & & & & & & & & $47(5.2)$ & $72(4.7)$ \\
\hline omit & $7(2.3)$ & $15(5.0)$ & & $17(3.4)$ & & $18(2.3)$ & & $10(2.0)$ & $52(4.7)$ & & & & & & & \\
\hline $\int$ & & & & & & & & & & $5(5.0)$ & & $466(5.4)$ & & & & \\
\hline
\end{tabular}

\footnotetext{
${ }^{4}$ As mentioned in footnote 3 above, the results of goodness test which was administrated in collaboration with the phonetic perception test are not incorporated in our discussion. The observation that the modal responses of goodness rates displayed by Appendix B are substantially inconsistent with those of perception prevents us from integrating the experimental results to our analysis.
} 